\title{
USO DA MIRTAZAPINA NO TRATAMENTO DA NÁUSEA E VÔMITO REFRATÁRIOS A TERAPIA HABITUAL APÓS DERIVAÇÃO GÁSTRICA EM Y DE ROUX
}

\section{Intractable nausea and vomiting following Roux-en-Y gastric bypass controlled with mirtazapine}

\author{
Alexandre Coutinho Teixeira de FREITAS, Júlio Cezar Uili COELHO
}

ABCDDV/588

Freitas ACT, Coelho JCU. Uso da mirtazapina no tratamento da náusea e vômito refratários a terapia habitual após derivação gástrica em Y de Roux. ABCD Arq Bras Cir Dig 2008;21(1):41-3

RESUMO - Racional - A cirurgia bariátrica é procedimento com significativa morbidade. A náusea a vômito geralmente ocorrem devido à presença de complicações mecânicas como as estenoses das anastomoses. Alguns casos apresentam sintomas importantes na ausência dessas complicações. Objetivo - Relato do uso da mirtazapina no pós-operatório de cirurgia bariátrica em um paciente com náuseas de vômitos refratários ao tratamento clínico habitual, na ausência de complicações mecânicas. Relato do caso - Paciente portador de obesidade mórbida foi submetido à derivação gástrica em Y de Roux laparoscópica. Evoluiu com náusea persistente associada a episódios de vômitos refratários a ondansetron, metoclopramida e bromoprida. Não foram identificadas causas mecânicas para o quadro. Foi iniciado mirtazapina $\left(\right.$ Remeron $\left.^{\circledR}\right)$ via oral na dose de $30 \mathrm{mg}$ por dia durante 60 dias. Após dois dias do início da medicação foi observado melhora total do quadro. A mirtazapina é um antidepressivo que apresenta efeito antiemético através do bloqueio de receptores para a serotonina (5-HT3) no centro do vômito no tronco cerebral. Conclusão - A mirtazapina pode ser útil nos casos de náusea e vômito refratários à terapia antiemética habitual no pós-operatório de derivação gástrica em Y de Roux, quando causas mecânicas são excluídas.

DESCRITORES - Derivação gástrica. Náusea. Vômito. Obesidade mórbida. Mirtazepina

\section{INTRODUÇÃO}

A derivação gástrica em Y de Roux é bastante efetiva no tratamento da obesidade mórbida. No entanto, complicações ocorrem em até $30 \%$ dos casos $^{12}$. A ocorrência de náusea e vômito no pós-operatório pode causar importante déficit nutricional e normalmente está relacionada à complicações mecânicas.

Esse estudo tem como objetivo descrever o caso de um paciente no pós-operatório de derivação gástrica em $\mathrm{Y}$ de Roux que apresentou náusea e vômito intensos de causa não mecânica, intratável com os antieméticos habituais, e que apresentou boa resposta com mirtazapina.

\section{RELATO DO CASO}

Homem, 24 anos, portador de obesidade mórbida refratária ao tratamento clínico, com índice de massa corporal de $46,1 \mathrm{Kg} / \mathrm{m}^{2}$, peso de $135 \mathrm{~kg}$ e altura de 171

Trabalho realizado no Serviço de Cirurgia do Aparelho Digestivo do Hospital de Clínicas da Universidade Federal do Paraná, Curitiba, PR, Brasil

Correspondência: Alexandre Coutinho Teixeira de Freitas - E-mail alexandrefreitas@ufpr.br cm. Apresentava como co-morbidades hipertensão arterial controlada com medicamento e hipertrigliceridemia. Foi submetido à derivação gastro-jejunal em Y de Roux laparoscópica pela técnica de Wittgrove. No $6^{\circ}$ dia de pósoperatório foi diagnosticada pequena fístula da anastomose gastrojejunal que fechou após sete dias. Inicialmente apresentou boa aceitação da dieta líquida. Após quatro dias surgiu quadro de náusea persistente associada a episódios de vômitos. Foi investigado com radiografia contrastada do esôfago, estômago e duodeno, endoscopia digestiva alta, ultrasonografia e exames laboratoriais que foram todos negativos. Não foram demonstradas evidências de estenose, fístula, abscesso, distúrbio metabólico ou qualquer outra causa que justificasse os sintomas, incluindo o uso de medicações. Foram utilizados, sem sucesso, medicamentos antieméticos habituais: metoclopramida, bromoprida e ondansetrona. Devido à intensidade do quadro o paciente apresentou acentuada perda de peso $(23 \mathrm{Kg})$ em 30 dias. Após esse período, foi iniciado mirtazapina (Remeron ${ }^{\circledR}$ ) via oral na dose de $30 \mathrm{mg}$ por dia durante 60 dias. Após dois dias do início da tratamento foi observado melhora total do quadro. O paciente encontra-se assintomático após a suspensão da medicação. Houve diminuição no ritmo de perda de peso e atualmente apresenta boa aceitação na evolução da dieta. 


\section{DISCUSSÃO}

O centro de controle do vômito está localizado no tronco cerebral e é ativado a partir de uma região rica em quimioreceptores. Os relacionados à ativação do centro do vômito são: o 5-HT3 (serotonin type-3), o H1 (histamine type-1), o M1 (muscarinic cholinergic type-1), o D2 (dopamine type-2), o NK1 (neurokinin type-1) e receptores opióides². Quimioreceptores H1 e M1 também estão presentes no labirinto e podem ativar o centro do vômito.

As drogas antieméticas disponíveis exercem seus efeitos bloqueando um ou mais quimioreceptores no centro do vômito $^{2,8}$. As butirofenonas, como o droperidol, bloqueiam os receptores D2. As benzamidas, como o cloridrato de metoclopramida e a bromoprida, também bloqueiam os receptores D2. Apresentam ainda efeito pró-cinético no estômago, no esôfago e no intestino. Em doses elevadas bloqueiam os receptores para a serotonina. As fenotiazinas, como a prometazina, bloqueiam os receptores $\mathrm{D} 2$ no centro do vômito e em outras áreas do sistema nervoso central. Os anti-histamínicos, como o dimenidrinato, suprimem a sensação vestibular de movimento; a difenidramina apresenta ainda efeito anticolinérgico e sedativo. Os anticolinérgicos, como a escopolamina, bloqueiam receptores M1 no córtex e na ponte e receptores H1 no hipotálamo e no centro do vômito. Os antagonistas da serotonina, como o ondansetron, bloqueiam os receptores 5-HT3. Os corticóides, entre eles a dexametasona, apresentam ação antiemética devido a mecanismo ainda não totalmente esclarecido. Acredita-se que exerçam ação antagonista às prostaglandinas e que promovam a liberação de endorfinas que causam melhora do humor e da sensação de bem estar e que estimulam o apetite.

A mirtazapina foi inicialmente descrita no tratamento da depressão. Exerce seus efeitos através do bloqueio dos receptores pós-sinápticos 5-HT2 e 5-HT3 e do receptor présináptico $\alpha 2$ e do estímulo do receptor pós-sináptico $5-\mathrm{HT}^{8}{ }^{8}$. O bloqueio do receptor 5-HT3 exerce ação anti-serotoninérgica responsável pelo seu efeito antiemético ${ }^{8}$. A primeira descrição do uso da mirtazapina como droga antiemética foi realizada em 1997 em pacientes utilizando inibidores da recaptação da serotonina ${ }^{9}$. Posteriormente, foi usada como droga antiemética em outras situações: na quimioterapia, no pós-operatório e na hiperemese gravídica ${ }^{4,15}$.

Existem poucos relatos do uso da mirtazapina no pósoperatório de cirurgia bariátrica. Um estudo demonstrou bons resultados em dois pacientes submetidos a derivação gástrica em Y de Roux tratados com $30 \mathrm{mg}$ por dia durante dois e oito meses respectivamente ${ }^{15}$. Apresentavam quadro importante de náusea e vômito e foram excluídas causas mecânicas através de estudo radiológico contrastado e endoscopia. Houve desaparecimento dos sintomas poucos dias após o início da medicação. Outros medicamentos como a bromoprida e a ondansetrona foram utilizados sem sucesso. Em outro relato, um paciente na terceira semana de pós-operatório de derivação gástrica em Y de Roux iniciou quadro severo de náuseas e de vômitos eventuais ${ }^{4}$. A investigação laboratorial e através de exames de imagem não demonstrou anormalidades. Foi tratado sem sucesso com ondansetrona, prometazina, droperidol e metoclopramida. Foi iniciado $30 \mathrm{mg}$ via oral de mirtazapina com melhora significativa do quadro após dois dias e mantida até completar dois meses de tratamento. Após a suspensão da medicação não foi observada recidiva do quadro. Uma outra descrição do uso de mirtazapina refere-se a paciente que apresentou no pós-operatório quadro caracterizado como transtorno alimentar sem outra especificação associado a transtorno obsessivo-compulsivo ${ }^{1}$. Essa paciente apresentava vômitos auto-induzidos, distorção da imagem corporal, anemia, desnutrição e medo intenso de ganho de peso apesar de ter perdido mais de $50 \%$ do seu peso inicial. A mirtazapina promoveu melhora do quadro nessa situação devido ao seu efeito antidepressivo. Os dois primeiros relatos apresentaram quadro clínico, investigação complementar e evolução após o tratamento muito semelhante ao descrito no presente estudo.

No pós-operatório de cirurgia bariátrica diversas complicações estão associadas à presença de náuseas e vômitos. As mais freqüentes são as causas mecânicas, como: a estenose da anastomose gastrojejunal, as úlceras de boca anastomótica, as hérnias internas, as bridas, as fístulas e os abscessos $^{12}$. Essas complicações normalmente apresentam quadro clínico sugestivo ou são detectadas na investigação com exames complementares. O mesmo ocorre em relação à síndrome de dumping cujos sintomas estão relacionados com a qualidade dos alimentos e a velocidade de ingestão. No caso relatado no presente estudo não foi detectado qualquer anormalidade que pudesse justificar o quadro.

Um diagnóstico que deve ser considerado é a gastroparesia do estômago excluso. Essa situação, bem como a gastroparesia do estômago reduzido, já foi relatada por alguns autores ${ }^{11,14}$. Manifesta-se através de náuseas, distensão e dor abdominal. A investigação com exames de imagem geralmente é negativa. Existe limitação de acesso ao estômago excluso com exames complementares. Em alguns casos pode-se visualizar distensão gástrica no exame radiológico simples, tomografia ou ultrasonografia do abdômen, porém esse achado é inespecífico. A cintilografia com administração via oral do radiofármaco é o exame de escolha para o diagnóstico da gastroparesia ${ }^{13}$. No entanto permite somente o estudo do estômago reduzido. $\mathrm{O}$ mesmo ocorre em relação ao teste respiratório com carbono após ingestão de refeição sólida. A endoscopia com duplo balão permite o acesso ao estômago excluso e a realização de procedimentos como a gastrostomia endoscópica para fins de nutrição, investigação ou descompressão ${ }^{10}$. Isso pode ser útil em alguns casos de gastroparesia que não apresentam resolução com medidas conservadoras. Recentemente a cintilografia hepato-biliar foi descrita como método diagnóstico em um relato de caso de gastroparesia do estômago excluso ${ }^{14}$. Durante o exame foi detectado refluxo de tecnésio para o estômago que apresentava atonia. Após duas horas ainda havia atividade cintilográfica no mesmo, o que é característico da gastroparesia. Esse caso foi manejado com drogas antieméticas habituais sem sucesso. Houve controle sintomático somente após a realização de gastrostomia percutânea descompressiva guiada por ultrasom. 
A gastroparesia é resultado do excesso de estímulo inibitório ou falência neuromuscular sobre os componentes do processo de esvaziamento gástrico ${ }^{13}$. Em $33 \%$ dos casos sua causa é idiopática; em $24 \%$ é devido ao uso de medicamentos como anticolinérgicos, opióides, L-dopa e anti-depressivos tricíclicos; em $24 \%$ é devido à diabete e em $19 \%$ é pós-operatória ${ }^{3}$. Entre os casos de causa pós-operatória, a vagotomia está associada ao rápido esvaziamento gástrico de líquidos e lento de alimentos sólidos ${ }^{13}$. Esse fator deve ser considerado no pós-operatório de derivação gastrojejunal em Y de Roux. A dissecção realizada na pequena curvatura do estômago para $\mathrm{o}$ acesso à sua parede posterior com a finalidade de realizar o primeiro disparo do grampeador, pode causar lesão hiatrogênica de ramos do nervo vago. Fatores hormonais também devem ser considerados, porém não existem estudos específicos sobre esses hormônios como causa de gastroparesia no estômago excluso. Em pacientes obesos foi demonstrado que a incretina GLP-1 reduz a velocidade de esvaziamento gástrico, o apetite e a ingestão de alimentos e diversos estudos demonstram o aumento de GLP-1 no pós-operatório de derivação gástrica em Y de Roux ${ }^{5,6,7}$. O GLP-1 é produzido pelas células L do íleo e do cólon. Em situação fisiológica é secretado na fase final do processo de digestão com o objetivo de limitar a ingestão de alimentos. A derivação gástrica em Y de Roux promove o estímulo precoce e aumento da secreção de GLP-1 devido ao trânsito rápido do bolo alimentar até as porções terminais do intestino delgado e do cólon. Isso poderia promover retardo do esvaziamento gástrico e sintomas como náuseas e distensão abdominal ainda durante a ingestão de alimentos. Outros hormônios gastrointestinais como a grelina e o peptídeo YY apresentam efeitos sobre a velocidade de esvaziamento gástrico. Alterações desses hormônios também foram descritas no pós-operatório de derivação intestinal em Y de Roux.

\section{CONCLUSÃO}

A mirtazapina é um antidepressivo que apresenta efeito antiemético através do bloqueio de receptores para a serotonina (5-HT3). Pode ser útil nos casos de náusea e vômito refratários a terapia antiemética habitual no pósoperatório de derivação gástrica em Y de Roux quando causas mecânicas são excluídas.

Freitas ACT, Coelho JCU.Intractable nausea and vomiting following Roux-en-Y gastric bypass controlled with mirtazapine. ABCD Arq Bras Cir Dig 2008;21(1):41-3

ABSTRACT - Background - Bariatric surgery is related to significant morbidity. Mechanical complications such as stricture of the anastomotic sites are the most common causes of persistent nausea and vomiting. Some patients present such symptoms in the absence of these complications. Aim - To report the use of mirtazapine in a patient submitted to bariatric surgery, presenting persistent nausea and vomiting in the absence of mechanical complications, and unresponsive to conventional antiemetic drugs. Case report - A morbidly obese patient submitted to laparoscopic Roux-en-Y gastric bypass presented persistent nausea and vomiting unresponsive to treatment with ondansetron, metoclopramide, and bromopride. No mechanical complications were identified. He was treated with an oral daily dose of $30 \mathrm{mg}$ of mirtazapine for 60 days. After two days, the patient presented significant clinical improvement. Mirtazapine is an effective drug most commonly used in the treatment of depression, presenting an antiemetic effect due to the blockade of 5-HT3 serotonin receptors in the brainstem. Conclusion - Mirtazapine can be useful in cases of Roux-en-Y gastric bypass that present nausea and vomiting unsuccessfully treated with conventional antiemetic drugs when mechanical causes are excluded.

HEADINGS - Gastric bypass. Nausea. Vomiting. Morbid obesity. Mirtazepine.

\section{REFERÊNCIAS}

1. Cordás TA, Lopes Filho AP, Segal A. Transtorno alimentar e cirurgia bariátrica: relato de caso. Arq Bras Endocrinol Metab 2004; 48:564-571.

2. Golembiewski J, Tokumaru S. Pharmacological prophylaxis and management of adult postoperative/postdischarge nausea and vomiting. J Perianesth Nurs 2006; 21:385-397.

3. Horowitz M, Su YC, Rayner CK, Jones KL. Gastroparesis: prevalence, clinical significance and treatment. Can J Gastroenterol 2001; 15: 805-813.

4. Huerta S, Siddiqui A. Intractable nausea and vomiting following Roux-en-Y gastric bypass: role of mirtazapine. Obes Surg 2006;16:1399.

5. Le Roux CW, Aylwin SJ, Batterham RL, Borg CM, Coyle F, Prasad V, Shurey S, Ghatei MA, Patel AG, Bloom SR. Gut hormones profiles following bariatric surgery favor an anoretic state, facilitate weight loss, and improves metabolic parameters. Ann Surg 2006; 243:108-114.

6. Morinigo R, Moize V, Musri M, Lacy AM, Navarro S, Marin JL, Delgado S, Casamitjana R, Vidal J. Glucagon-like peptide-1, peptide YY, hunger, and satiety after gastric bypass surgery in morbidly obese subjects. J Clin Endocrinol Metab 2006; 91:1735-1740.

7. Naslund E, King N, Mansten S, Adner N, Host JJ, Gutniak M, Hellstrom PM. Prandial subcutaneous injections of glucagon-like peptide-1 cause weight loss in obese human subjects. Br J Nutr 2004; 91:439-446.
8. Pae CU. Low-dose mirtazapine may be successful treatment option for severe nausea and vomiting. Prog Neuropsychopharmacol Biol Psychiatry 2006; 30:1143-1145.

9. Pederesen L, Klysner R. Antagonism of selective serotonin reuptake inhibitorinduced nausea by mirtazapine. Int Clin Psychopharmacol 1997;12:59- 60.

10. Ross AS, Semrad C, Alverdy J, Waxman I, Dye C. Use of double-balloon enteroscopy to perform PEG in the excluded stomach after Roux-en-Y gastric bypass. Gastrointest Endosc 2006; 64:797-800.

11. Samin KA, Alam I, Riaz S, Alam S, Baxter JN. Gastro-ileal stenosis and gastroparesis after a biliopancreatic diversion. Obes Surg 2006; 16:1243-1245.

12. Schauer PR, Ikramuddin S, Gourash W, Ramanathan R, Luketich J. Outcomes after laparoscopic Roux-en-Y gastric bypass for morbid obesity. Ann Surg 2000; 232:515-529.

13. Tack J. Gastric motor disorders. Best Pract Res Clin Gastroenterol 2007; 21:633-644.

14. Tarakji AM, Morales F, Rovito P. Hepatobiliary scintigraphy as a diagnostic modality for gastroparesis of the bypassed stomach after gastric bypass for morbid obesity. Obes Surg 2007; 17:414-415.

15. Teixeira FV, Novaretti TM, Pilon B, Pereira PG, Breda MF. Mirtazapine (Remeron) as treatment for non-mechanical vomiting after gastric bypass. Obes Surg 2005;15:707-709.

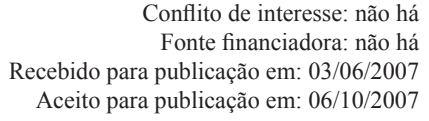

Conflito de interesse: não há Aceito para publicação em: 06/10/2007 